\title{
A self assembled monolayer based microfluidic sensor for urea detection
}

\author{
Saurabh Srivastava, ${ }^{a b}$ Pratima R. Solanki, ${ }^{a}$ Ajeet Kaushik, ${ }^{a}$ Md. Azahar Ali, ${ }^{a}$ Anchal Srivastava ${ }^{b}$ \\ and B. D. Malhotra*a
}

\author{
Received 4th March 2011, Accepted 15th April 2011 \\ DOI: 10.1039/c1nr10240k
}

\begin{abstract}
Urease (Urs) and glutamate dehydrogenase (GLDH) have been covalently co-immobilized onto a self-assembled monolayer (SAM) comprising of 10-carboxy-1-decanthiol (CDT) via EDC-NHS chemistry deposited onto one of the two patterned gold $(\mathrm{Au})$ electrodes for estimation of urea using poly(dimethylsiloxane) based microfluidic channels $(2 \mathrm{~cm} \times 200 \mu \mathrm{m} \times 200 \mu \mathrm{m})$. The CDT/Au and Urs-GLDH/CDT/Au electrodes have been characterized using Fourier transform infrared (FTIR) spectroscopy, contact angle (CA), atomic force microscopy (AFM) and electrochemical cyclic voltammetry $(\mathrm{CV})$ techniques. The electrochemical response measurement of a Urs-GLDH/CDT/Au bioelectrode obtained as a function of urea concentration using $\mathrm{CV}$ yield linearity as 10 to $100 \mathrm{mg} \mathrm{dl}^{-1}$, detection limit as $9 \mathrm{mg} \mathrm{dl}^{-1}$ and high sensitivity as $7.5 \mu \mathrm{AmM}^{-1} \mathrm{~cm}^{-2}$.
\end{abstract}

\section{Introduction}

Electrochemical microfluidic biosensing devices have been found to provide powerful platforms for desired biochemical and chemical analysis due to many advantages such as low reagent use, ease-of-fabrication, miniaturization, low reaction time, improved sensitivity, selectivity, and continuous monitoring of desired analytes. ${ }^{1}$ Many materials such as glass, silicon, polymer materials and quartz have been used for fabrication of the desired microfluidic devices. Among the various polymeric materials, poly (dimethylsiloxane) (PDMS) and poly(methyl methacrylate) (PMMA) have been found to have great potential for large-scale fabrication due to excellent electrical/chemical resistivity. ${ }^{2}$ Many microfluidic systems have recently been reported for many applications such as enzymatic analysis, immunoassays, ${ }^{3}$ lab-on-achip, ${ }^{4}$ DNA analysis and separation, ${ }^{5}$ capillary electrophoresis, ${ }^{6}$ etc. based on optical and electrochemical techniques. The electrochemical techniques are however found to provide accurate and sensitive information and are compatible with the microsystems. ${ }^{1}$

Self-assembled monolayers (SAMs) are formed by spontaneous organization of thiolated molecules on a desired metal surface whose varied composition, structure and properties can be varied rationally. Due to the inherent ordered arrangement at nanoscale, good electronic transport, controllable optical/electrical properties and availability of functional groups, SAMs have recently become very important for immobilization of desired biomolecules for biosensing and bioelectronics

${ }^{a}$ Department of Science and Technology Centre on Biomolecular Electronics, Biomedical Instrumentation Section, National Physical Laboratory, New Delhi, 110012, India. E-mail: bansi.malhotra@gmail. com; Fax: +91-011-45609310; Tel: +91-011-45609152

${ }^{b}$ Department of Physics, Banaras Hindu University, Varanasi, 221005, India application. ${ }^{7}$ Moreover, controlled immobilization of a desired biomolecule onto a SAM requires very small amounts with proper orientation and desired analytes can be easily detected via various transduction modes. ${ }^{8}$ Besides this, SAMs can be utilized to prevent protein denaturation at an electrode surface for obtaining enhanced stability of biomolecules. ${ }^{9}$ Many SAMs containing carboxy or amino groups have been used to immobilize proteins for biosensor application. Furthermore, the protonation-deprotonation behavior of the carboxylic acid terminated SAM is strongly influenced by the topography of the adsorbed surface. ${ }^{10}$

The performance of a biosensor critically depends on the surface properties of a material, availability of functional groups, mode of enzyme immobilization and activity of an enzyme on the electrode surface. ${ }^{11,12}$ The modification of free terminal groups of thiolated SAMs with biomolecules using physical adsorption may result in denaturation and loss of activity of the desired biomolecules. However, binding of a biomolecule using a chemical activator arising due to the resultant covalent bond may lead to increased stability of a biosensor. The chemical modification of a SAM using an activator can be achieved by various crosslinkers like $N$-ethyl- $N$-(3-dimethylaminopropyl) carbodiimide/ $N$-hydroxysuccinimide (EDC/NHS), glutaraldehyde, glyoxal, dimethyl pimelimidate and sulfosuccinimidyl-2-( $p$-azidosalicylamido) ethyl-1, $3^{\prime}$-dithiopropionate. ${ }^{7}$ The majority of these crosslinkers act as a spacer between a biomolecule and the matrix that may affect sensitivity and the detection range of a sensor. EDC/ NHS has recently been employed for chemical modification of desired surfaces for biosensor fabrication. It has been found that EDC/NHS activated SAMs provide improved immobilization of biomolecules and biosensing characteristics since they provide direct linkage between the two molecules with no intervening linker or spacer. ${ }^{13}$ Moreover, activation of $-\mathrm{COOH}$ group of 
a SAM by EDC/NHS provides uniform binding of $-\mathrm{NH}_{2}$ group of a desired biomolecule without much aggregation.

Estimation of urea in blood/urine is of much interest in biomedical and clinical analysis. The normal level of urea in blood varies from 15 to $40 \mathrm{mg} \mathrm{dl}^{-1}\left(2.5-7.5 \mathrm{mM} \mathrm{l}^{-1}\right)$. An increase in urea level in blood and urine causes renal failure, urinary tract obstruction, dehydration, shock, burns and gastrointestinal bleeding. Moreover, decreased urea concentration causes hepatic failure, nephritic syndrome, cachexia (low-protein and highcarbohydrate diets). ${ }^{14,15}$ Apart from clinical applications, there is a growing demand for availability of the robust, reliable instrumentation for estimation of urea in food products and environment. Urea biosensors are generally based on the application of urease (Urs) that catalyzes decomposition of urea into hydrogen bicarbonate and ammonium ions $\left(\mathrm{NH}_{4}{ }^{+}\right)$. It is found that ammonium ions easily diffuse into the solution. Thus it is necessary to add glutamate dehydrogenase $(\mathrm{GLDH})$ as it catalyzes the reaction between $\mathrm{NH}_{4}{ }^{+}, \alpha$-ketoglutarate $(\alpha-\mathrm{KG})$ and nicotinamide adenine di-nucleotide (NADH) to produce $\mathrm{NAD}^{+}$and L-glutamate. ${ }^{15-17}$

Many matrices such as polypyrrole, ${ }^{18}$ polyethylenimine, ${ }^{19}$ polyvinylferrocenium, ${ }^{20}$ chitosan, ${ }^{21}$ amine functionalized glassy carbon $^{22}$ and nanocomposites like chitosan and zinc oxide/iron oxide, ${ }^{17,23}$ polyvinyl alcohol-polyacrylamide composite, ${ }^{24}$ poly ( $N$-3-aminopropylpyrrole)-co-pyrrole, ${ }^{25}$ polyaniline-Nafion ${ }^{\circledR} /$ Au composite, ${ }^{26}$ poly $(N$-vinyl carbazole $) /$ stearic acid,${ }^{27}$ polyaniline-poly $(n$-butylmethacrylate $)$ composites,${ }^{28}$ and polyanilineperfluorosulfonated ionomer composite ${ }^{15}$ have been utilized to fabricate urea biosensors. However, there is a considerable scope to fabricate urea biosensor with improved characteristics.

We report results of the studies relating to co-immobilization of Urs-GLDH onto CDT-SAM to detect urea by the electrochemical technique using PDMS based microchannels. To the best of our knowledge this is the first report on SAM based microfluidic biosensor for urea detection.

\section{Results and discussions}

The Fourier Transform Infrared (FTIR) spectra (Fig. 1A) of CDT fabricated onto the $\mathrm{Au}$ substrate (Curve a) exhibits symmetric and asymmetric $\mathrm{C}-\mathrm{H}$ stretching modes (corresponding to methylene group) at 2858 and $2915 \mathrm{~cm}^{-1}$. The characteristic peaks seen at 1127,1717 and $3350 \mathrm{~cm}^{-1}$ represent stretching modes of $\mathrm{C}-\mathrm{O}, \mathrm{C}=\mathrm{O}$ and $\mathrm{O}-\mathrm{H}$ bonds respectively. The band seen at $662 \mathrm{~cm}^{-1}$ is due to $\mathrm{C}-\mathrm{S}$ stretching vibration. A sharp peak seen at $1266 \mathrm{~cm}^{-1}$ represents $\mathrm{CH}_{2}$ wagging of the $-\mathrm{CH}_{2}-\mathrm{S}-$ bond.

The FTIR spectrum of Urs-GLDH immobilized CDT/Au electrode (Curve b) exhibits bands at $1631 \mathrm{~cm}^{-1}$ (corresponding to $\mathrm{N}-\mathrm{H}$ stretching in amide II), $1262 \mathrm{~cm}^{-1}$ (corresponding to $\mathrm{C}-\mathrm{N}$ stretching and $\mathrm{N}-\mathrm{H}$ bending modes of amide $\mathrm{I}$ bands) and $1061 \mathrm{~cm}^{-1}$ (assigned to $\mathrm{C}-\mathrm{O}$ stretching) due to amide bonds in protein revealing immobilization of Urs-GLDH onto CDT/Au.

The contact angle (CA, Fig. 1B) measurements have been carried out to understand the hydrophilic/hydrophobic nature of the surface before and after the immobilization of enzyme by the Sessile drop method using a drop shape analyzer. The value of CA for the bare $\mathrm{Au}$ (image a) is found to be $90.5^{\circ}$ indicating hydrophobic nature of the Au surface. After the SAM formation (image b), the value of $\mathrm{CA}$ decreases to $86^{\circ}$ indicating hydrophilic nature of the surface attributed to presence of the highly polar carboxylate terminal group of CDT. The further decrease in the value of contact angle to $30^{\circ}$ observed in the case of the UrsGLDH/CDT/Au bioelectrode (image c) indicates immobilization of the enzymes (Urs and GLDH) onto the CDT/Au substrate.

The surface topology of the CDT/Au electrode (image a) and the Urs-GLDH/CDT/Au electrode (image b) has been investigated using atomic force microscopy (AFM) (Fig. 1C) in the tapping mode. The AFM image of the CDT/Au electrode (image a) shows that CDT molecules are uniformly distributed onto the Au surface (average roughness $0.746 \mathrm{~nm}$, data not shown) resulting in a rough nanoporous structure with an average roughness of $2.82 \mathrm{~nm}$. However, after the co-immobilization of enzymes (Urs and GLDH) the rough nanoporous morphology of the CDT/Au electrode changes into a regular nanoporous morphology (image b) with an average roughness of $4.97 \mathrm{~nm}$ revealing that nanoporous morphology of SAM provides a favorable environment for adsorption of Urs and GLDH molecules. Moreover, the average maximum height for the CDT/Au electrode increases from 19.4 to $34.2 \mathrm{~nm}$ after enzyme immobilization of Urs and GLDH onto the CDT/Au electrode via electrostatic interactions. The change in average height (dimension) of immobilized enzymes i.e. urease (7.5 $\mathrm{nm} \times 8.0 \mathrm{~nm} \times 8.0 \mathrm{~nm})^{29}$ and GLDH $(6.0 \mathrm{~nm} \times 4.5 \mathrm{~nm} \times 4.5$ $\mathrm{nm})^{30}$ onto the CDT/Au electrode is about $14.8 \mathrm{~nm}$.

The electrochemical impedance spectroscopy (EIS) technique measures impedance of the electrode surface as a function of frequency due to variation in interfacial properties of the interface of the electrode. A Faradic impedance spectrum (Nyquist plot) includes a semicircle region observed at higher frequency corresponding to the electron-transfer limited process on the $Z^{\prime}$ axes and is followed by a straight line at $45^{\circ}$ to the real axes at lower frequencies revealing the diffusion-limited electron transfer process. The complex impedance can be presented as a sum of the real $\left(Z^{\prime}\right)$ and imaginary $\left(Z^{\prime \prime}\right)$ components that mainly originate from the resistance and capacitance of the cell including ohmic resistance of the solution $\left(R_{\mathrm{s}}\right)$, Warburg impedance $\left(Z_{\mathrm{W}}\right)$, capacity of the electric double layer $\left(C_{\mathrm{d} 1}\right)$, and surface electron transfer resistance $\left(R_{\mathrm{CT}}\right)$. The modification of the electrode surface results in change in the value of $R_{\mathrm{CT}}$. In the EIS, the semicircle part corresponds to the electron-transfer limited process as its diameter is equal to the electron transfer resistance $\left(R_{\mathrm{CT}}\right)$ that controls electron transfer kinetics of the redox probe at the electrode interface. ${ }^{31,32}$

Fig. 2A shows the Nyquist diagrams of the CDT/Au electrode and the Urs-GLDH/CDT/Au bioelectrode in a PBS solution containing $5 \mathrm{mM}\left[\mathrm{Fe}(\mathrm{CN})_{6}\right]^{3-/ 4-}$ in the frequency range from 0.01 to $10^{5} \mathrm{~Hz}$. It can be seen that $R_{\mathrm{CT}}$ value $(10.25 \mathrm{k} \Omega$, Curve a) obtained from the semicircle of the CDT/Au electrode increases after immobilization of Urs-GLDH onto the CDT/Au electrode $(15.1 \mathrm{k} \Omega)$. This suggests that immobilized Ur-GLDH molecules strongly bind with the CDT SAM and block charge carriers in the SAM. These results indicate the immobilization of Urs and GLDH onto the CDT/Au electrode.

The electrochemical studies of both CDT/Au electrode and UrsGLDH/CDT/Au bioelectrode have been studied using cyclic voltammetry (CV, Fig. 2B) in PBS containing $5 \mathrm{mM}\left[\mathrm{Fe}(\mathrm{CN})_{6}\right]^{3-/ 4-}$. It can be seen that cyclic voltammogram (Curve a) shows welldefined redox behavior at $0.35 \mathrm{~V}$. The magnitude of the response current obtained for the Urs-GLDH/CDT/Au electrode (Curve b) further decreases resulting due to insulating characteristics of 


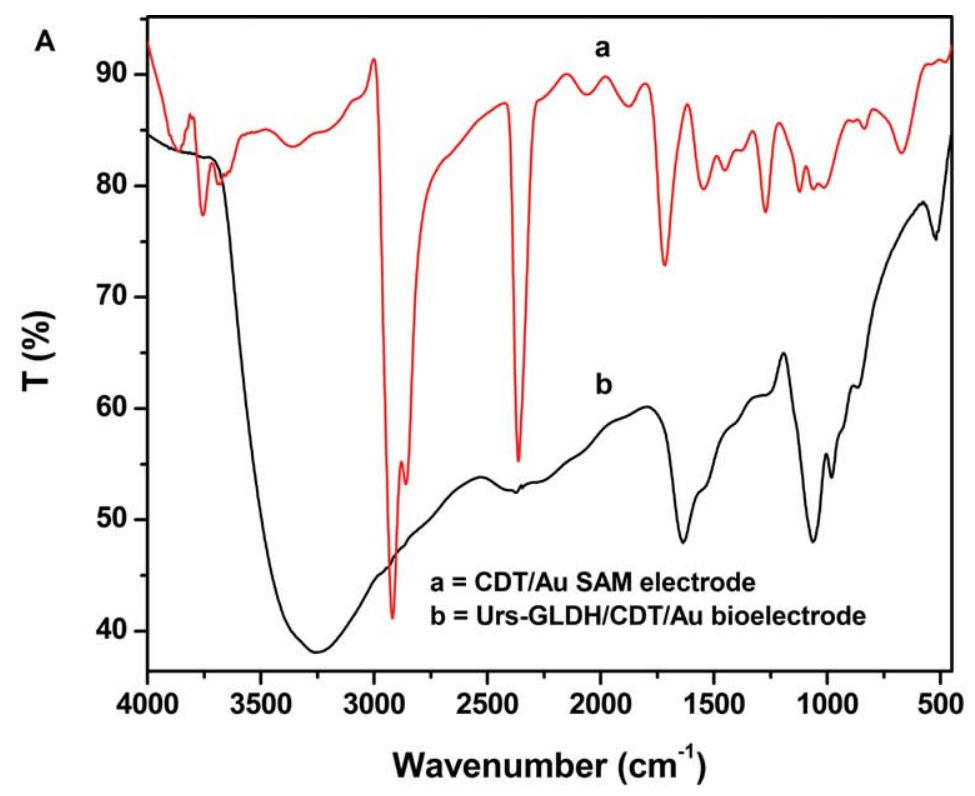

B
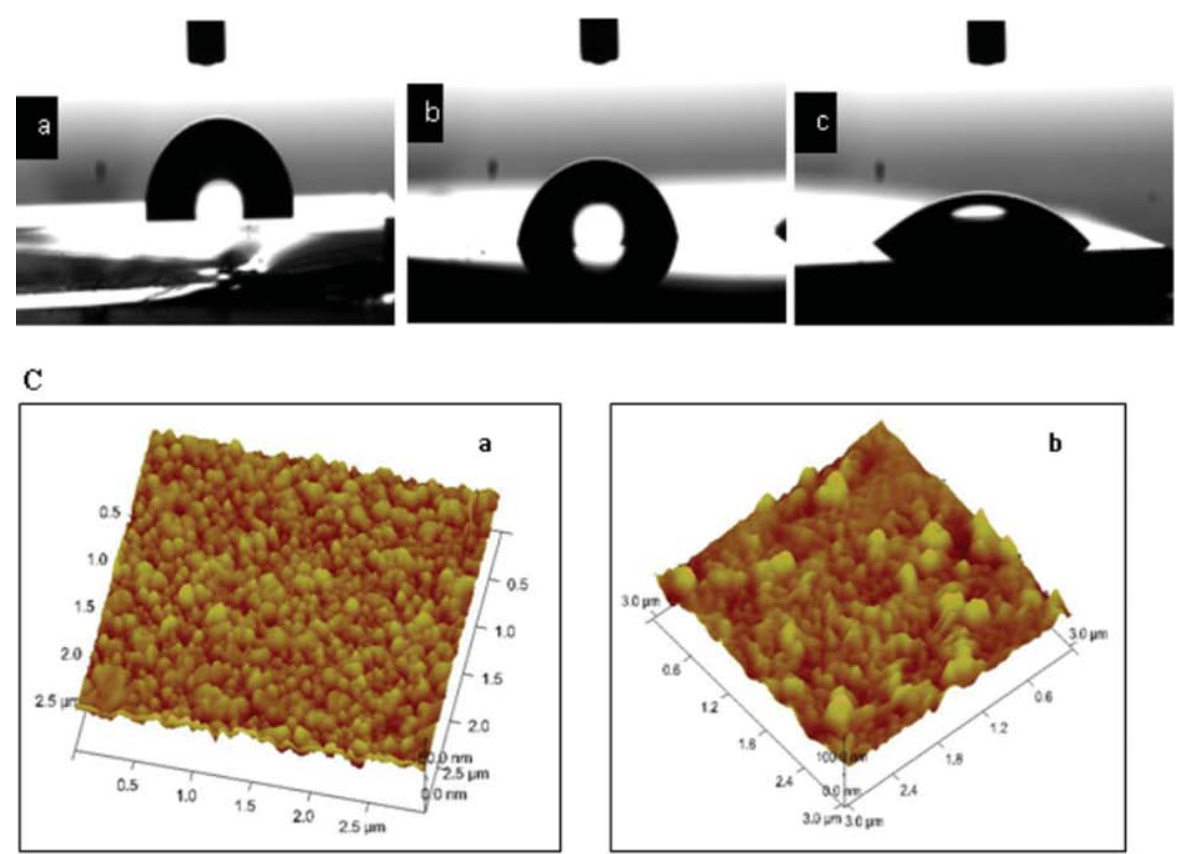

Fig. 1 (A) FTIR spectra of CDT/Au electrode (Curve a) and Urs-GLDH/CDT/Au bioelectrode (Curve b). (B) Contact angle studies of bare Au electrode (image a), CDT/Au electrode (image b) and Urs-GLDH/CDT/Au bioelectrode (image c). (C) Atomic force microscopy (AFM) images of CDT/ $\mathrm{Au}$ electrode (image a) and Urs-GLDH/CDT/Au bioelectrode (image b).

the enzymes (Urs and GLDH) indicating immobilization of Urs-GLDH onto the CDT/Au electrode via electrostatic interactions.

The effect of $\mathrm{pH}$ on Urs-GLDH/CDT/Au bioelectrode has been carried out using the $\mathrm{CV}$ technique (inset (i), Fig. 2B). The magnitude of current response of the Urs-GLDH/CDT/Au bioelectrode becomes maximum at $\mathrm{pH} 7$ revealing maximum activity at the $\mathrm{pH} 7$ at which Urs retains its natural structure and is responsible for low detection limit and high sensitivity for urea detection. The results of electrochemical experiments repeated at least 20 times have been found to be reproducible.
Fig. 3A shows results of the electrochemical response studies of the Urs-GLDH/CDT/Au bioelectrode obtained as a function of urea concentration in the presence of nicotinamide adenine dinucleotide (NADH, $3.7 \mathrm{mg} \mathrm{dl}^{-1}$ ) and $\alpha$-keto glutamate $(\alpha-\mathrm{KG}$, $\left.47.5 \mathrm{mg} \mathrm{dl}^{-1}\right)$ in a PBS solution containing $\left.5 \mathrm{mM}\left[\mathrm{Fe}(\mathrm{CN})_{6}\right]^{3-14-}\right\}$ carried out using the cyclic voltammetry technique at a continuous flow rate of $20 \mu \mathrm{l} \mathrm{min}{ }^{-1}$ in the PDMS microchannel. The effective working area of the working Urs-GLDH/CDT/Au bioelectrode is $0.12 \mathrm{~cm}^{2}$.

During the biochemical reaction, hydrolysis of urea is catalyzed by urease that releases ammonium ions $\left(\mathrm{NH}_{4}{ }^{+}\right)$as shown 

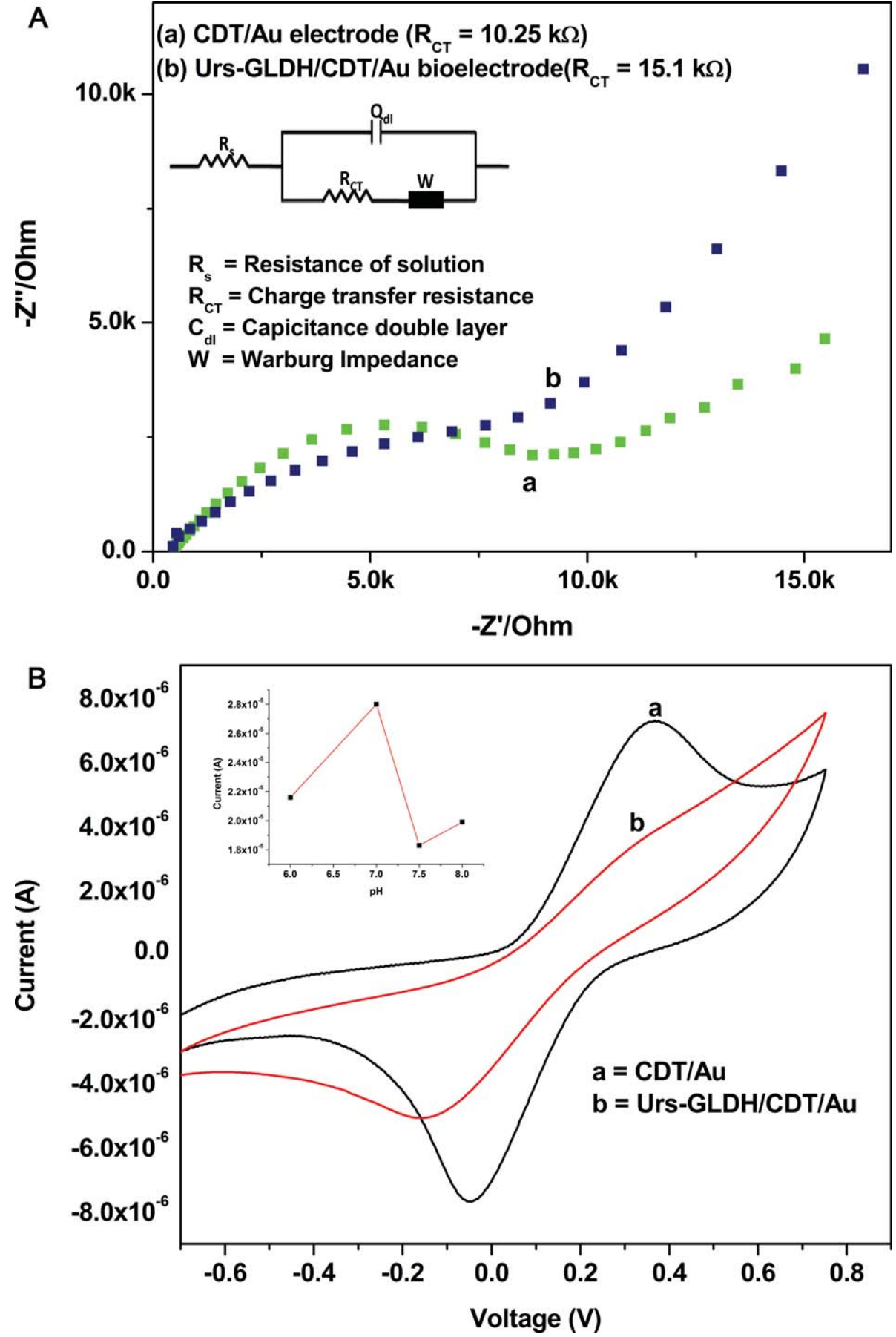

Fig. 2 (A) Electrochemical impedance spectroscopy (EIS) studies of CDT/Au electrode (Curve a) and Urs-GLDH/CDT/Au bioelectrodes (Curve b). (B) Cyclic voltammetry (CV) of CDT/Au electrode (Curve a) and Urs-GLDH/CDT/Au bioelectrode (Curve b). Inset (i): CV response of Urs-GLDH/ CDT/Au bioelectrode as a function of $\mathrm{pH}(6-8)$.

in the first step of the given biochemical reaction. These $\mathrm{NH}_{4}^{+}$ ions are coupled with $\alpha-\mathrm{KG}$ in the presence of GLDH and $\mathrm{NADH}$ that acts as a cofactor that generates L-glutamate and $\mathrm{NAD}^{+}$. $\mathrm{NAD}^{+}$is utilized in the reverse reaction, involving $\mathrm{L}^{-}$ glutamate by conversion into $\alpha-\mathrm{KG}$ and free $\mathrm{NH}_{4}{ }^{+}$via oxidative deamination reaction. The electrons generated during the biochemical reactions are transferred to the CDT/Au electrode via $\mathrm{Fe}(\mathrm{III}) / \mathrm{Fe}(\mathrm{IV})$ redox species resulting in output signal in the form of current.

$$
\left(\mathrm{NH}_{2}\right)_{2} \mathrm{CO}+3 \mathrm{H}_{2} \mathrm{O} \stackrel{\text { urease }}{\longrightarrow} 2 \mathrm{NH}_{4}^{+}+\mathrm{OH}^{-}+\mathrm{HCO}_{3}^{-}
$$

$\mathrm{NH}_{4}^{+}+\alpha$-ketoglutarate $+\mathrm{NADH} \stackrel{\text { GLDH }}{\longrightarrow}$ L-glutamate $+\mathrm{NAD}^{+}$

The calibration curve has been fitted between concentration of urea and the magnitude of anodic peak current $\left(I_{\mathrm{a}}\right)$. It is observed that $I_{\mathrm{a}}$ value increases linearly (eqn (3)) as urea concentration increases (Fig. 3B) and can be represented as 

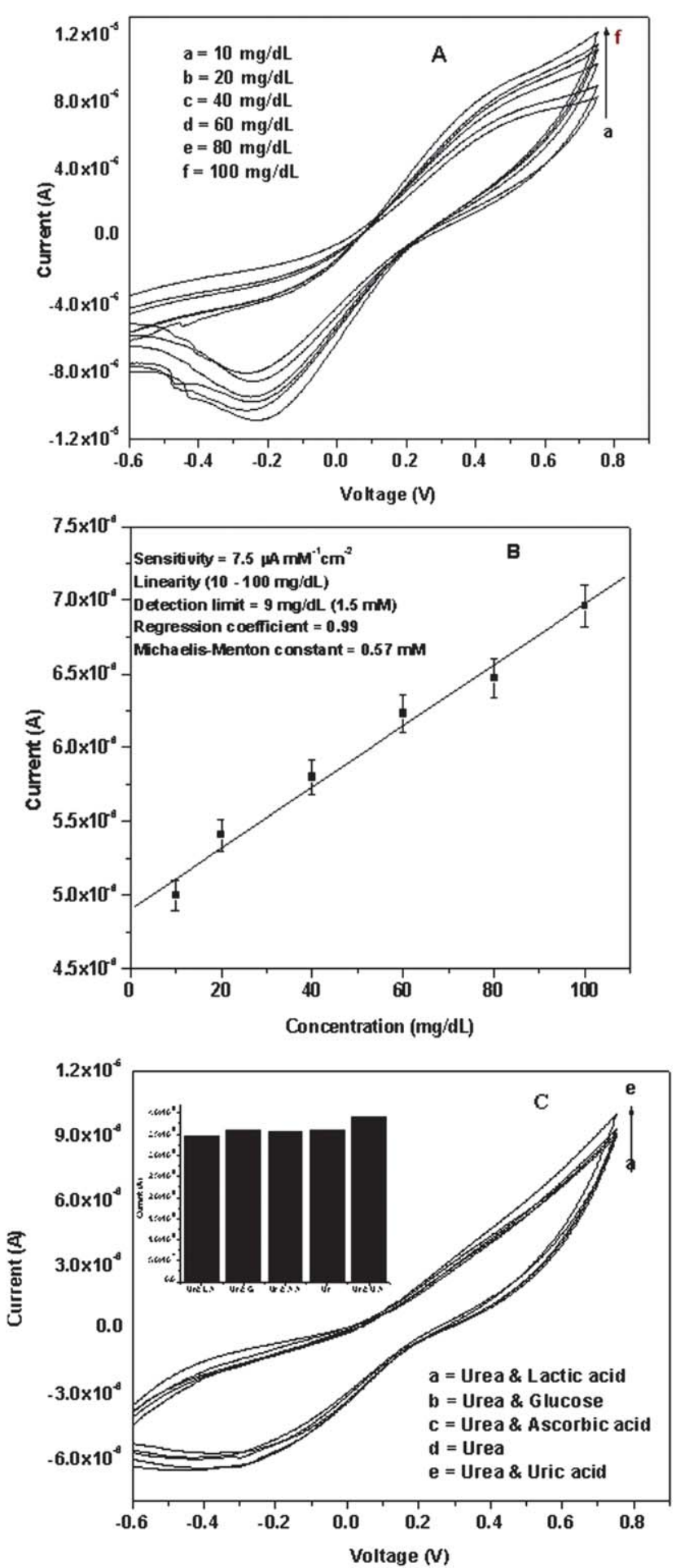

Fig. 3 (A) CV response of Urs-GLDH/CDT/Au bioelectrode as a function of urea concentration. (B) Calibration curve between magnitude of anodic peak current $\left(I_{\mathrm{a}}\right)$ and urea concentration. $(\mathrm{C})$ The effect of interferents on electrochemical response of Urs-GLDH/CDT/Au bioelectrode.

$I_{\mathrm{a}}(A)=6.8 \times 10^{-6} A+2.56 \times 10^{-8} A \mathrm{mg}^{-1} \mathrm{dl} \times[$ urea concentration $\left(\mathrm{mg} \mathrm{dl}^{-1}\right)$ ]

The Urs-GLDH/CDT/Au bioelectrode exhibits linearity as $10-100 \mathrm{mg} \mathrm{dl}^{-1}$ with detection limit as $9 \mathrm{mg} \mathrm{dl}^{-1}$ and a response time of $10 \mathrm{~s}$. The sensitivity of Urs-GLDH/CDT/Au bioelectrode is estimated as $7.5 \mu \mathrm{A} \mathrm{mM}{ }^{-1} \mathrm{~cm}^{-2}$ with the value of regression coefficient as 0.995 . The value of the apparent MichaelisMenten constant $\left(K_{\mathrm{m}}\right)$ calculated using the Lineweaver-Burk plot $(1 /$ I versus $1 /[C])$, has been found to be $0.57 \mathrm{mM}$ for the immobilized Urs-GLDH/CDT/Au bioelectrode indicating maximal catalytic activity of the enzyme at low substrate concentration.

The shelf-life of the Urs-GLDH/CDT/Au bioelectrode has been monitored by measuring electrochemical current response with respect to time, with a regular interval of 1 week. It is observed that this bioelectrode retains about $90 \%$ of the enzymes (Urs and GLDH) activity even after about 10 weeks when stored in refrigerated conditions $\left(4^{\circ} \mathrm{C}\right)$ after which the current response decreases to $85 \%$ in about 12 weeks.

The effect of interferents onto the Urs-GLDH/CDT/Au bioelectrode has been determined by measuring the current response by adding normal concentration of interferents (Fig. 3C) like ascorbic acid $(0.05 \mathrm{mM})$, uric acid $(0.1 \mathrm{mM})$, glucose $(100 \mathrm{mg}$ $\left.\mathrm{dl}^{-1}\right)$ and lactic acid $(5 \mathrm{mM})$ along with urea $(1 \mathrm{mM})$ in phosphate buffer $(50 \mathrm{mM}, \mathrm{pH} 7,0.9 \% \mathrm{NaCl})$ at the same flow rate using a microchannel. The current response remains nearly the same except for uric acid wherein there is an increase of about $8 \%$.

The sensing performance of the Urs-GLDH/CDT/Au bioelectrode based urea biosensor has been summarized in Table 1 along with those reported in the literature.

\section{Conclusions}

10-Carboxy-1-decanthiol (CDT) based self-assembled monolayer fabricated onto a patterned Au electrode has been utilized to co-immobilize urease and GLDH for urea detection using the electrochemical technique in PDMS microfluidic channel. It exhibits linearity in the concentration range of $10-100 \mathrm{mg} \mathrm{dl}^{-1}$, lower detection limit of $9 \mathrm{mg} \mathrm{dl}^{-1}$, response time of $10 \mathrm{~s}$, and improved sensitivity of $7.5 \mu \mathrm{A} \mathrm{mM} \mathrm{mM}^{-1} \mathrm{~cm}^{-2}$ with the value of regression coefficient as 0.995 . This electrochemical microfluidic urea biosensor shows negligible influence of interferents and hence it can be used to detect urea in samples containing other analytes. This CDT-SAM based microfluidic biosensor can be used for estimation other analytes such as glucose, cholesterol, low density, etc. Efforts should be made to investigate dependence of response of the CDT-SAM based microfluidic sensor on various other parameters including flow rate, diffusion coefficient, etc.

\section{Experimental section}

\section{Materials}

All the chemicals namely urease (Urs), glutamate dehydrogenase (GLDH), nicotinamide adenine dinucleotide (NADH), $\alpha$-ketoglutarate $(\alpha$-KG), $\quad N$-hydroxysuccinimide (NHS), ethyl(dimethylaminopropyl) carbodiimide (EDC), and 10-carboxy-1-decanthiol (CDT) have been procured from Sigma-Aldrich(USA). Sylgard 184 is from Dow Corning (Midland, MI, USA). SU-8-100 negative photoresist and SU-8 developer from Microchem (Newton, MA, USA).

Urs $\left(10 \mathrm{mg} \mathrm{ml}^{-1}\right)$ and GLDH $\left(1 \mathrm{mg} \mathrm{dl}^{-1}\right)$ solutions are freshly prepared in phosphate buffer $(50 \mathrm{mM}, \mathrm{pH}$ 7). The stock solution 
Table 1 Sensing characteristics of CDT-SAM based microfluidic urea biosensor along with those reported in the literature

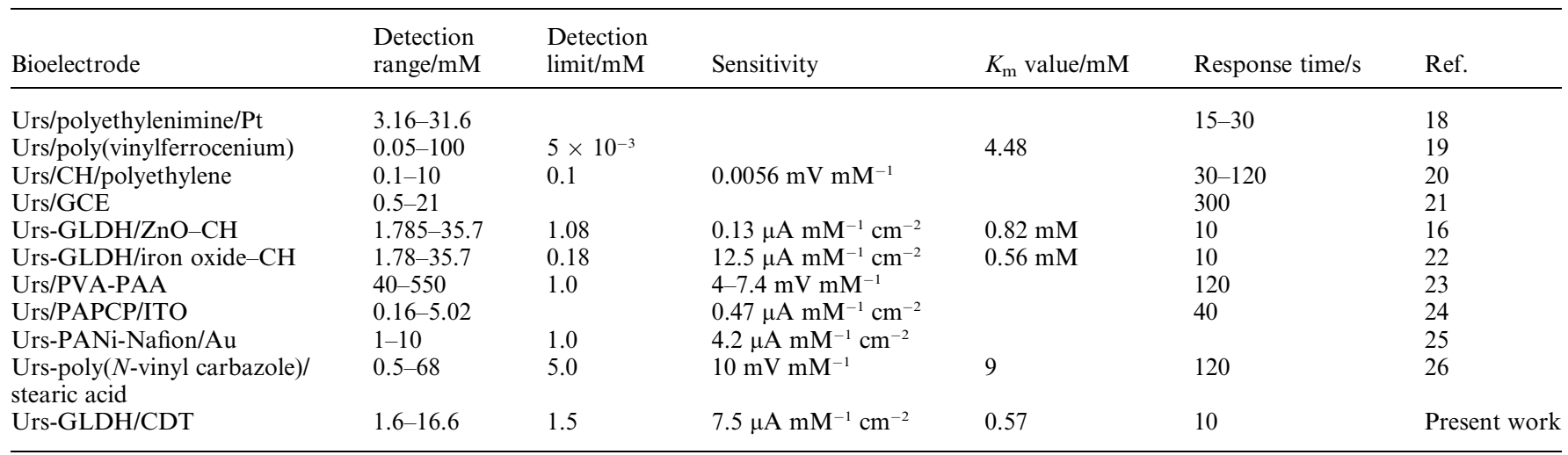

of urea $\left(100 \mathrm{mg} \mathrm{dl}^{-1}\right)$ is prepared in deionized water and is kept at $4{ }^{\circ} \mathrm{C}$. This stock solution has been used to make different concentrations of urea by further dilution. EDC $\left(100 \mathrm{mg} \mathrm{ml}^{-1}\right)$, NHS $\left(20 \mathrm{mg} \mathrm{ml}{ }^{-1}\right)$, NADH $\left(3.7 \mathrm{mg} \mathrm{dl}^{-1}\right)$, and $\alpha-\mathrm{KG}$ $\left(47.5 \mathrm{mg} \mathrm{dl}^{-1}\right)$ are freshly prepared in doubly distilled water.

\section{Fabrication of microfluidic channels}

The PDMS microchannels have been fabricated using a soft lithographic technique by following various steps like cleaning of Si wafers, spin coating of photoresist, pre and post-exposure heat treatment, UV exposure and development to obtain a positive relief pattern of the photoresist over Si wafers (called Master) of desired dimensions $(2 \mathrm{~cm} \times 200 \mu \mathrm{m} \times 200 \mu \mathrm{m})$. The PDMS oligomer and a cross-linking agent are mixed in $10: 1$ ratio, stirred vigorously for about $5 \mathrm{~min}$, and then degassed for $30 \mathrm{~min}$ under vacuum to remove air bubbles. The clear solution is poured onto the Master and is heated at 100 ${ }^{\circ} \mathrm{C}$ for $1.5 \mathrm{~h}$. The PDMS layer with the pattern of the negative relief is peeled off from the Master and is cut into suitable size.
The reservoirs are fabricated by punching holes at the ends of microchannels.

\section{Fabrication of patterned working electrodes}

A gold $(\mathrm{Au})$ coated glass plate $(2 \mathrm{~cm} \times 3 \mathrm{~cm})$ has been taken. Three patterned electrodes comprising of dimension $(0.2 \mathrm{~cm} \times$ $2 \mathrm{~cm}$ ) have been prepared onto the gold plate by rapid marker masking using gold and chrome etchants. ${ }^{33}$ The working electrodes modified with CDT-SAM have been used to immobilize urease (Urs) and glutamate dehydrogenase (GLDH) for urea detection. Bare gold $(\mathrm{Au})$ is taken as a counter electrode. A silver wire $(0.4 \mathrm{~mm}$ dia. $)$ coated with silver chloride $(\mathrm{AgCl})$ layer is taken as a reference electrode (Scheme 1). A sketch of desired pattern is hand drawn over a gold plate with the permanent marker. The ink acts as a mask that protects the gold layer below it from the aqueous acid etchant. The remaining gold is removed by dipping the substrate into gold and chrome etchants (20 $\mathrm{s}$ and $10 \mathrm{~s}$, respectively) and is cleaned with acetone and water. The PDMS chip is tightly clamped with the glass

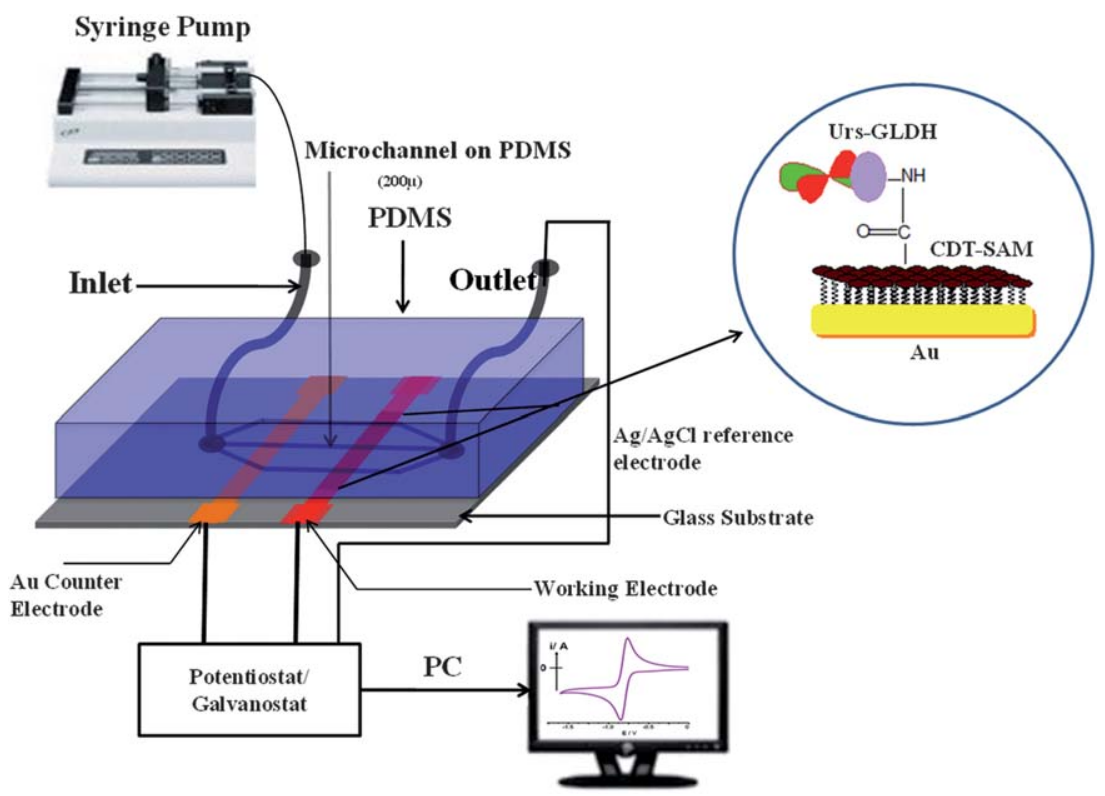

Scheme 1 Microfluidic module for SAM based electrochemical urea biosensor. 
substrate containing patterned electrode to ensure leakage-free flow operation (Scheme 1).

\section{Formation of self-assembled monolayer over the CDT/Au bioelectrode}

The fabricated patterned gold electrodes are cleaned using a piranha solution $\left(7 \mathrm{H}_{2} \mathrm{SO}_{4}: 3 \mathrm{H}_{2} \mathrm{O}_{2}\right)$. The SAM of CDT is formed by immersion of the electrode into a $1 \mathrm{mM}$ ethanol solution of CDT for about $24 \mathrm{~h}$. The SAM modified Au electrodes are rinsed successively with ethanol and water several times and then dried under the stream of nitrogen.

\section{Covalent immobilization of Urs and GLDH onto the CDT/Au SAM electrode}

Urs and GLDH are covalently attached to the CDT/Au electrode by activating $\mathrm{COOH}$ group of CDT using EDC as the coupling agent and NHS as an activator. The EDC-NHS-activated $\mathrm{COOH}$ group binds with the $\mathrm{NH}_{2}$ group of Urs and GLDH resulting in the formation of a covalent amide bond $(\mathrm{CO}-\mathrm{NH})$. For $\mathrm{COOH}$ activation, the CDT/Au electrode is first dipped in PBS containing 0.4 M EDC and 0.1 M NHS for about $4 \mathrm{~h}$ at room temperature $\left(25^{\circ} \mathrm{C}\right)$. Further, $10 \mu \mathrm{l}$ of bi-enzyme solution containing Urs $\left(10 \mathrm{mg} \mathrm{ml}^{-1}\right)$ and $\operatorname{GLDH}\left(1 \mathrm{mg} \mathrm{ml}^{-1}\right)$ in $1: 1$ ratio \{prepared in phosphate buffer (PBS $50 \mathrm{mM}, \mathrm{pH} 7$ ) $\}$ is immobilized by uniformly spreading on the activated CDT/Au electrode and is kept for about $6 \mathrm{~h}$. The Urs-GLDH/CDT/Au bioelectrode is then washed with PBS buffer containing 0.05\% Tween 20 and is stored at $4{ }^{\circ} \mathrm{C}$ when not in use.

\section{Instrumentation}

Fourier transform infrared (FTIR, Perkin-Elmer, Model 2000) studies have been used for characterization of both CDT/Au electrode and Urs-GLDH/CDT/Au bioelectrode. The hydrophilic/hydrophobic nature of the CDT/Au electrode and the UrsGLDH/CDT/Au bioelectrode has been tested by contact angle (Model OCA 15EC, Dataphysics instruments Gmbh, Germany) using deionized distilled water. The surface morphologies of fabricated CDT SAM and immobilization of Urs-GLDH onto CDT SAM have been investigated using atomic force microscopy (AFM, Veeco, Nanoscope Model).

Electrochemical studies such as cyclic voltammetry (CV) and electrochemical impedance spectroscopy (EIS) have been performed within the microfluidic chip containing the patterned CDT/Au electrode and Urs-GLDH/CDT/Au bioelectrode that have been connected to Autolab, Potentiostat/Galvanostat. The solution comprises of PBS ( $\mathrm{pH} 7$ ) containing $\alpha-\mathrm{KG}, \mathrm{NADH}$ and urea of different concentrations that are separately prepared in vials and then injected into the microchannels under continuous flow using the syringe pump during the measurements. The electrochemical response studies have been conducted under a continuous solution flow using a syringe pump (Harvard apparatus, PHD 2000) at a constant flow rate of $20 \mu 1 \mathrm{~min}^{-1}$.

\section{Acknowledgements}

We thank Prof. R. C. Budhani, Director, National Physical Laboratory, New Delhi, India, for providing the facilities.
Authors SS, PRS, AK are thankful to Council of Scientific \& Industrial Research (CSIR) and Department of Science and Technology (DST), India, for the award of Junior Research Fellowship, Young Scientist and Senior Research Fellowship, respectively. Financial support received under the DST sponsored project (DST/TSG/ME/2008/18) is gratefully acknowledged.

\section{References}

1 B. V. Chikkaveeraiah, H. Liu, V. Mani, F. Papadimitrakopoulos and J. F. Rusling, Electrochem. Commun., 2009, 11, 819.

2 D. C. Duffy, J. C. McDonald, O. J. A. Schueller and G. M. Whitesides, Anal. Chem., 1998, 70, 4974.

3 J. S. Rossier and H. H. Girault, Lab Chip, 2001, 1, 153.

4 S. Haeberle and R. Zengerle, Lab-on-a-Chip, 2007, 7, 1094.

5 L. Koutny, D. Schmalzing, O. S. Solano, S. E. Difrawy, A. Adourian, S. Buonocore, K. Abbey, P. McEwan, P. Matsudaira and D. Ehrlich, Anal. Chem., 2000, 72, 3388.

6 Q. Xue, A. Wainright, S. Gangakhedkar and I. Gibbons, Electrophoresis, 2001, 22, 4000.

7 S. K. Arya, P. R. Solanki, M. Datta and B. D. Malhotra, Biosens. Bioelectron., 2009, 24, 2810.

8 F. Cheng, L. J. Gamble and D. G. Castner, Anal. Chem., 2008, 80, 2564.

9 A. K. M. Kafi, D. Y. Lee, S. H. Park and Y. S. Kwon, Microchem. J., 2007, 85, 308 .

10 M. Tominaga, K. Miyahara, K. Soejima, S. Nomura, M. Matsumoto and I. Taniguchi, J. Colloid Interface Sci., 2007, 313, 135.

11 M. Gerard, K. Ramanathan, A. Chaubey and B. D. Malhotra, Electroanalysis, 1999, 11, 450.

12 A. Kumar, Rajesh, A. Chaubey, S. K. Grover and B. D. Malhotra, J. Appl. Polym. Sci., 2001, 82, 3486.

13 Z. Matharu, A. J. Bandodkar, G. Sumana, P. R. Solanki, E. M. I. Mala Ekanayake, K. Kaneto, V. Gupta and B. D. Malhotra, J. Phys. Chem. B, 2009, 113, 14405.

14 J. V. D. Melo, S. Cosnier, C. Mousty, C. Martelet and N. J. Renault, Anal. Chem., 2002, 74, 4037.

15 W. J. Cho and H. J. Huang, Anal. Chem., 1998, 70, 3946.

16 A. Maaref, H. Barhoumi, M. Rammah, C. Martelet, N. JaffrezicRenault, C. Mousty and S. Cosnier, Sens. Actuators, B, 2007, 123, 671.

17 P. R. Solanki, A. Kaushik, A. A. Anees, G. Sumana and B. D. Malhotra, Appl. Phys. Lett., 2008, 93, 163903.

18 S. B. Adeloju, S. J. Shaw and G. G. Wallace, Anal. Chim. Acta, 1997, 341, 155.

19 B. Lakard, G. Herlem, S. Lakard, A. Antoniou and B. Fahys, Biosens. Bioelectron., 2004, 19, 1641.

20 F. Kuralay, H. Ozyoruk and A. Yildiz, Sens. Actuators, B, 2005, 109, 194.

21 J. M. C. S. Magalhaes and A. A. S. C. Machado, Talanta, 1998, 47, 183.

22 X. Wang, H. Watanabe, N. Sekioka, H. Hamana and S. Uchiyama, Electroanalysis, 2007, 19, 1300.

23 A. Kaushik, P. R. Solanki, A. A. Ansari, G. Sumana, S. Ahmad and B. D. Malhotra, Sens. Actuators, B, 2009, 138, 572.

24 S. K. Jha, A. Topkar and S. F. D’Souza, J. Biochem. Biophys. Methods, 2008, 70, 1145.

25 Rajesh, V. Bisht, W. Takashima and K. Kaneto, Biomaterials, 2005, 26, 3683

26 Y. C. Luo and J. S. Do, Biosens. Bioelectron., 2004, 20, 15.

27 R. Singhal, A. Gambhir, M. K. Pandey, S. Annapoorni and B. D. Malhotra, Biosens. Bioelectron., 2002, 17, 697.

28 M. M. C. Ortega, D. E. Rodriguez, J. C. Encinas, M. Plascencia, F. A. M. Velarde and R. Olayo, Sens. Actuators, B, 2002, 85, 19.

29 K. Z. Hossain, C. M. Monreal and A. Sayari, Colloids Surf., B, 2008, 62, 42.

30 J. J. Birktoft, F. Miake, L. J. Banaszak and C. Frieden, J. Biol. Chem., 1979, 254, 4915.

31 A. H. Liu, M. D. Wie, I. Honma and H. S. Zhou, Anal. Chem., 2005, 77, 8068.

32 Z. Tong, R. Yuan, Y. Chai, Y. Xie and S. Chen, J. Biotechnol., 2007, 128, 567.

33 D. P. Manica and A. G. Ewing, Electrophoresis, 2002, 23, 3735 . 